\title{
Making Decision in Open Communities: Collective Actions in the Public Realm
}

\author{
Anna De Liddo ${ }^{1}$. Grazia Concilio ${ }^{2}$
}

Published online: 18 August 2017

(C) Springer Science+Business Media B.V. 2017

\begin{abstract}
This special issue is comprised of five articles which explore the modes and forms of decision-making in open communities, i.e. in organizations having loosely coupled, often informal, structures with flexible and permeable boundaries. These communities are emerging in the public realm and performing actions which can be described as a collective. More and more of these organizational environments are perceived to be highly democratic, innovative, and leading to successful social innovations, cohesion processes and governance. The articles represent an attempt to capture the nature of decision environments specific to open communities, and the dynamics of their decisions. The articles discuss characteristics of these communities and how they enable more democratic decisions and, at the same time, identify decision-making constraints that create obstacles for effective collective actions.
\end{abstract}

Keywords Decision-making in open communities · Collective actions · Public realm

\section{Growing Phenomena of Open Communities' Action}

The need for transparency and inclusiveness of decision-making in the public realm is growing and challenging the organizational and governance structure of decision agents while the collective's actions are framed and conceptualized. Further nurturing the several critiques already build on Olson (1971), discussion related to the logic

Grazia Concilio

grazia.concilio@polimi.it

Anna De Liddo

anna.deliddo@open.ac.uk

1 Knowledge Media Institute, The Open University, Walton Hall, Milton Keynes MK7 6AA, UK

2 DAStU Politecnico di Milano (IT), Piazza Leonardo da Vinci 26, 20133 Milano, Italy 
of collective action is given. Individuals increasingly expect to be active protagonists of transformations and changes, that are either already happening or are necessary at local and global scale. Individuals seldom work in isolation; they rather collaborate with other key actors with whom they connect in an attempt to solve common issues. The practical need to face challenges and act in the real world is what brings people together in "open communities" of action. This tendency is mainly discussed by the literature in terms of activism (Pattie et al. 2003; Vromen 2003; Kavanaugh et al. 2005; Flanagin et al. 2006; Yau 2011) thus confirming Anderson's findings (1999) and demonstrating the open nature of the public sphere. This process of individual and collective self-involvement can explain some important phenomena observed and analysed in the literature (for different observation lenses on this, see Staeheli 2008; Hayes-Conroy 2008; Carmo and Estevens 2017) and is giving rise to the emergence of new practices of the collective action in the public realm.

When these communities emerge in the public realm, the interplay between the "individual" and the "collective" becomes rich and productive, especially thanks to the "proneness to openness" of the involved actors, such as public and private parties (municipalities and individuals), to act outside and free from existing organisational constraints.

Open communities in the public realm have been identified in many different contexts and as a result of different types of (social) innovation initiatives. They have been described as living labs (Følstad 2008; Mulder 2012; Leminen 2013) and the related communities have some characteristics that differentiate them from others, especially when exploring their decision-making styles and dynamics.

\subsection{Open Communities' Abilities and Decision-making Modes}

More and more we are witnessing the action of communities having permeable boundaries and being able to be operationally effective (Hou 2010; Concilio and Molinari 2015), even if their members are not permanently involved in the communities' activities and dynamics. Such communities may show effective self-organization abilities and unexpected collective intelligence (Schuler 2010), creativity and innovation. But they also exhibit difficulties in achieving a coordinated mode of action due to some misaligning conditions challenging potentials and opportunities for collective intelligence to emerge and become effective.

They usually act in the public realm whenever interests regarding collective goods are mobilized or their uses are discussed, regulated and managed (Clark 2000). In some cases, they can converge towards a collective action, in other cases they show exactly the opposite dynamics and they negatively affect actions in the public sphere. Some questions related to this need to be explored, for example: what are the open communities that act in the public realm? how do they form? why do they succeed and when to they fail? how do they make decisions?

When such communities achieve a coordinated mode of action, they may have a full insurgent nature, they may bloom and grow autonomously and still show, in some cases, a relevant capacity to interact with institutional agents thus affecting the general governance of decision making. Also, they may represent the intentional 
outcome of planned actions aimed at widening and opening specific decision-making processes towards experimental models of democracy. However, in some cases, such communities show dispersed and misaligned actions; in these cases, decision-making models fail any rational interpretation and do not achieve any relevant goal of the public realm.

Also, these (open) communities show important proneness to experimental action in the public realm (Ostrom 2006). They are important innovation drivers at many different levels: they challenge decision-making governance models by creating a strict linkage between decision-making and decision implementation which is in the nature of experimental approaches. By so doing they reduce the distance between decision-making and action, thus reformulating forms and models of both decisions and actions.

All these communities, implement innovation initiatives involving some sort of collective vision. They follow complex, interesting and innovative decision-making processes, which are hardly described by traditional models of decision-making theory. Here are some of the characteristics:

- An ephemeral value: the experimental nature of the collective action introduces anomalies in the decision-making governance as well as in decision-making routines as they are more oriented to learning from the action experiments rather than a precise and specific action;

- No unique clear decision maker: developed throughout actions of unclear accountability, they involve public bodies of standard public decision-making protocols, where decisions are a sort of patchworked output of micro, distributed, not contradicting intentions aligned throughout the collective action;

- The chance to deal with the complexity of differences in values and understanding: the cognitive and value richness of environments where collective actions take place, can generate new knowledge or new combinations of knowledge with promising innovation potentials.

\subsection{Unexplored Issues}

These loosely coupled groups of individuals, not belonging to a uniquely structured organisation can: (1) collaboratively act in a coordinated manner, (2) effectively transform established practices, and (3) collectively decide on the ways how to be inclusive and transparent (sometimes they come up with more ways than any other existing organisation acting in isolation).

When successful, these environments are perceived to be highly democratic, innovative, and leading to successful social innovation, cohesion processes and decision governance. Still, models and forms of decision-making in these open organizations have not been explored in depth and the following questions have not been addressed:

- What is the root causes of their success? What are the causes of failures?

- How do open communities self-manage and implement decisions, which often break the rules we know about mainstream decision-making in the public realm?

- What kinds of decision environments are specific to open communities?

- What decision-making processes take place in such environments? 
- To what extent these environments are effective to enable more democratic decisions?

- What is the role of technologies in facilitating collective deliberation and decisionmaking in these ephemeral contexts?

The Special Issue aims at exploring the above in five research contributions that analyse different decision contexts and processes characterized by the openness of the decision-making organizations involved as well as a variety of impacts on the public realm.

\section{Five Distinctive Factors of Open Communities' Action}

As a first step toward a more structured understanding of open communities' actions, we could implement a framework that can be used to inform individuals, communities and organisations about new ways to organise and make decisions, which lead to more inclusive, transparent and effective collective actions. This framework is based on the literature landscape presented in Sect. 1, and on the discussion of the papers presented in Sect. 3.

In order to develop a better understanding of the questions presented in the previous section five main items are identified. The first three dimensions help understanding the decision-making context, process and structure in which open organizations operate. The last two represent properties of most open communities' practices, i.e., democratic values (such as inclusion and transparency) and a distinctive attitude toward learning.

\subsection{Context}

Contexts in which open communities manifest themselves vary widely: from placebased groups (Larson and Lach 2008) to online open communication contexts (Faraj et al. 2011); from urban laboratories (Karvonen and Heur 2014) and urban public spaces interventions (Hou 2010) to strategic planning at different scales (Blair 2004). A key challenge for open organisations is that they involve different stakeholders, with different knowledge, values, objectives and different way to frame problems. Since the communities and organizations act in the public sphere, contexts are relevant as they motivate and shape their creation. Contexts represent the source and characterise the reason for their being and, at the same time, they constrain their way of operation. In some cases, contexts act as enablers of some experiments and attempts, while in others act as obstacles.

Contexts also represent relevant reference for open communities and organizations and their interpretation and understanding may affect the way in which such organizations make decisions and act. When the context is clarified by a top down decision (Concilio and Moro, this special issue) or by a clear action framework (Nogueira et al. this special issue) the emerging open communities act and experiment in a coordinated manner. At the same time, ambiguity about problem framing wrongly affects people's understanding of other actors in the same decision-making context. This often leads to decisions that are done on a simplified, wrong or incomplete understanding of other people's values, objectives and actions (Giordano et al. this special issue). 


\subsection{Process}

Collective actions in open communities are facilitated by a variety of processes that are often dependent on the context in which the organisation operates, the constraints it is subject to and the resources available. Some common denominators can be identified. Firstly, collective action often starts with an individual or group-sized "initiator". This initiator often gathers around a common goal, a shared problem, or value and it usually starts coordinating work with a series of face to face meetings and with on-line dialogue and communication (Emery and Flora 2006).

Meetings, call for interest, call for statements are key ways to expand the boundaries of the open organisation. Meetings are also relevant spaces of interaction with local actors (Concilio and Moro, this special issue).

Aside from meetings, experimental and testing activities are also often used to solicit interest. While building common ground and common understanding of the problem frames, dialogues are key factors to how open communities operate and make decision.

Effective collective action in open communities require "participants awareness of the others' ideas and opinions so that they can learn from each other and make good judgments" (Xiao et al. this special issue). This awareness is particularly challenging for open online communities in which participants often come and go at any time even with a faster and bigger rate that in face to face communities, and where participants have often never met or worked with each other. Computational techniques such as machine learning and argument mining can be used to develop awareness tools to "help the participants to make an informed judgment in evaluating issues and opinions" (Xiao et al. this special issue).

Finally, the effectiveness of collective actions in open communities is linked to the decision-making processes it builds upon. Only by combining and reconciling the different interests and points of view of the participants with the process of decisionmaking itself collective action can emerge.

The collaborative creation of documents containing guidelines (for design, actions or even simply as a way to communicate results), or the co-design of action plans are effectively used as means to reconcile views and coordinate actions. Foresight methodologies and other participatory methods can be also used to generate consensus and a collective vision along multiple long-term views (Nogueira et al. this special issue).

\subsection{Structure}

The structure in which decision-making and collective action occurs changes with the context and actors involved. They may be described as quasi-organizations: their structure, lightly formalized and loosely-coupled, allows them to be highly flexible and adaptable to contextual changes and un-expected needs or events. Having a structure, whatever light and flexible, gives them effective identity and recognisability so they can act as formal agents in the interaction with institutions as well as in the action in the public realm. At the same time, their very light structure, also including the 
temporary inclusion of external actors as volunteers, citizen professionals, supporters and activists, allows them to benefit from informal modes to act in the public realm out of constraining bureaucratic infrastructures, free of heavy organizational regulations and norms, inside effective governance models.

Furthermore, the presence of boundary objects (e.g. a physical public square, or a mediation tool or a human or methodological intervention) can be catalyst to the creation of effective temporary, ephemeral coordination spaces in which "doing" and "acting" are the mediation entities between value systems that otherwise would rise conflict conditions or absence of "communication" (see the trading zones concept in Concilio and Moro, this special issue). In Giordano at al. (this special issue) for instance the structure of the decision-making that lead to success is based on the mediated dialogue between the decision-making actors. In this case the mediation role was carried out by the researcher/analyst and the trading zone is the analytical framework the researchers used to analyse the context and engage in a critical dialogue with the participants.

Participatory approaches are recurrently promoted as systematic means to promote effective decision-making processes and decision-making tend to have superior value when participants are involved in deliberation processes (Nogueira et al. this special issue)

Successful decision-making and collective action structures are based on several phases, such as for instance the definition of short and longer term actions and the delineation of collective priorities. Each of these phases is carried out with different moments of participation, which can take the form of meetings, focus groups, workshops, or other collective activities of knowledge creation (such as writing up of guidelines, reports, carrying on events organisation, mapping exercises or other projects outputs).

When open communities operate online the structure in which collective action emerges is partially limited by the online environment, which results in a lack of knowledge of other participants. At the same time, online interaction enables a higher level analysis of the communications flow between participants. This can support key decisional steps such as gathering awareness of other people's opinion and tracking decision rationale (Xiao et al. this special issue).

\subsection{Democratic Values}

There is a set of distinctive democratic values around which open communities generate, coordinate, operate, make decision and act.

Dialogue, common ground, and awareness building are key factors to the success of the decision-making processes in these communities, while ambiguity and domain based knowledge are dividing factors. Relational-based knowledge and reasoning build though dialogue are key values or develop collective action (Giordano et al. this special issue).

Moreover, open organisations recognise that "knowledge and expertise needed to innovate do not entirely belong to the organization wherein innovation is developed", which implies that the organisation need to stay "open" to external knowledge and 
expertise (Scozzi et al. this special issue). These two factors characterise open communities for the "openness" to multiple actors, purposes, opportunities.

Research in open online communities evidences the importance of group dynamics in the way people present and argue their position. For instance, minority positions need to be defended in order to avoid dynamics such as the "spiral of silence" (NoelleNeumann 1974) in which people that sense they are in a minority position feel less comfortable to share their true opinion with the group (Xiao et al. this special issue). Open communities need to care about the long tail of participation, because this is where often innovation and intelligence generate.

Therefore, democracy and inclusion are not only key values to respect in open communities, they are also the key success factors that determine the effectiveness of collective actions.

Finally, transparency and inclusion are key in decision-making processes which lead to collective action in open communities. Open communities often decide and act in co-responsibility and power sharing contexts, for instance, processes promoted by not governmental organisations or organisations which have more horizontal and equitable distribution of power (Nogueira et al. this special issue). These values make open organisations inherently more democratic in nature, perspective and impact.

\subsection{Learning}

Due to their lightly formalized and loose-coupled structure, open communities are highly flexible and adaptable to contextual changes and unexpected needs or events. They usually act within experimental approaches, and co-create actions so generating new shared knowledge, which is at the basis of their being a collective entity. In these conditions, social learning occurs when reframing problems and reciprocal understanding happens between decision actors (Giordano et al. this special issue). Learning has the special meaning here of knowledge sharing and production. The learning and the co-produced knowledge represent the major self-produced resources open community becomes owners of; they are common goods representing the means open communities act in the public sphere.

Learning is intrinsically related to the way decisions are made. It is at the same time the main output of decisions and it represents the decisions' sometimes implicit goal: decisions made in open communities are highly embedded in action when action may be of any individual joining the community later on, i.e. entering the action and reshaping it in the course of the action itself, with others (Concilio and Moro, this special issue). Reframing and reshaping action is the way knowledge is shared and co-created.

Still learning may find obstacles. Sometimes learning does not occur when open communities fail. Giordano et al. (this special issue) describe the way ambiguity can deteriorate the full understanding of the context and, related to it, of the open community in terms of the openness with its multiplicity of values, understandings, behaviours, and interpretations. Under these conditions, learning fails and together with it the whole collective action: neither learning can be the output nor the scope of any decision. 


\section{Articles in the Special Issue}

The contribution by Scozzi, Bellantuono, and Pontrandolfo "Managing open innovation in urban labs" widen the reflection on the concept of open innovation focussing on ecosystems that emerge in public realm both when they are activated by both topdown actions or when they are the results of civic activism. The paper proposes and discusses the Urban Lab Methodology (ULM), which supports the management of urban labs by integrating Soft System Methodology with an open innovation framework previously developed by the authors and suggesting an association between the innovation context and appropriate open innovation practices. The article applies the framework to the context of Taranto (Italy) with the aim to analyse the process that brought to the creation of the Manifesto for the historical centre of the city and observe that the ULM has been partially adopted by the local actors out of a methodological framework rather in a spontaneous and self-organizing mode. This article shows how decision-making in urban labs also shape the organizational framework of the open contexts and impacts the availability to new external knowledge.

The article "Collaborative Decision-Making in Non-formal Planning Settings" by Nogueira, Borges, and Wolf looks at planning initiatives outside the formal planning system and suggests they constitute a favourable environment for implementing and analysing collaborative decision-making processes. In particular, the authors conceptualise the decision-making context in the light of the Policy Network analysis to better understand the underlining conditions, as well as their influence in the outcomes of the planning process itself. The article presents the case of Strategic Spatial Planning process in Adxtur territory in Portugal which has been supported by applying the AHP model to identify the complex mapping and formulation of priorities with respect to two different scenarios. The application of such a methodology is consistent with two different needs of decision-making in open environments namely, the need for transparency as well as the need for a shareable and easy to understand rationale.

“Toward the Automated Detection of Individuals' Rationales in Large-Scale Online Open Participative Activities: A Conceptual Framework", the article by Xiao, Stromer-Galley, and Sándor, discusses decision-making in Large-Scale Online Open Participative (LSOOP) environments and activities. In these environments participants can join and leave at any time, and often do not have a history of working together; here participants hardly follow the communication framework producing decisions and the authors propose a computational approach (combining computational techniques and awareness design methodology) that automatically identifies and extracts the rationales from LSOOP communication data and presents them to the participants through rationale-based awareness tools.

This contribution focusses on one of the most important challenge for decisionmaking in open environments: the difficulties of not stable (permanent) actors in the decision-making process to enter the history (rational) of the decision-making process to be effective and coherent with the process itself. The proposed computational approach represents an advanced contribution to the attempt to make communication and interaction rationale available in open decision environments and in particular it reflects on the Wikipedia open environment as a public realm action space. 
The article "Ambiguity in problem framing as a barrier to collective actions: some hints from groundwater protection policy in the Apulia Region" by Giordano, Brugnach, and Pluchinotta explores some specific conditions that do not enable an effective collective action to occur. It explores very peculiar kinds of open organizations, those responsible of ground water use at a regional scale. In particular, it describes a very complex decision-making systems where a not realistic multiscale governance model is supposed to exist by the policy makers who underestimate the decision-making models of some intermediary actors. This lack of awareness generates important consequences in terms of ambiguity at the different decision-making levels and results in the complete failure of the policy decision goal and in the no-emergence of a collective action.

This contribution proposes a methodological framework to analyse and describe the interactive space of an open community (in the specific case the regional community of actors dealing with ground water use, i.e. regional policy makers, water managers, and farmers) and explores the role of ambiguity as cause for a coordinated action to emerge.

The article by Concilio and Moro "Trading Zones and Public Spaces Transformations the Case of Piazza Leonardo in Milan" analyses interventions in urban public spaces as relevant contexts where decision-making is traditionally developed in closed environments. The authors, referring to an attempt made to open up the decisionmaking process for a public space transformation (the Piazza Leonardo da Vinci in Milano) by transferring it onto practices of urban space use, suggest the trading zones framework and the adoption of boundary objects as an interpretative framework. The article shows how the use of boundary objects and the intentional adoption of an experimental approach to the urban space transformation succeeded in setting up an open organization where decision-making is represented by a sequence of micro-decisions, each made by different actors and specifically oriented to keep space experiments as mode for urban transformation.

With this contribution, the idea of trading zones and the related use of boundary objects gains a prescriptive value for decision making, especially in those situations where a multiplicity of actors is involved, the collective value of the decision object is evident, and the openness of the action appears relevant for the success of the implementation.

\section{Future Research Pathways to Enabling Democratic Decision Making}

In a moment in which many thinkers are reflecting on democracy models and on the growing need for distributed democracy, the opportunity offered by the emergence of open communities and organizations in the public realm represents a crucial research environment. The five factors described to understand the open communities are also suggestive of a potential area of investigation contributing to the definition of more open and democratic decision-making environments in the public realm. Such research would need a strong experimental basis in which all subjects participate. These subjects would be involved in decision-making of public administration as well as local organizations and citizens' groups. Still a key role is played by local administrations 
and by their un-preparedness to challenge normative boundaries while conceiving and hosting experiments in decision-making which is strictly coded and normed, and rarely able to overcome voting models for democratic decision making.

Conceiving decisions as embedded in collective complex actions would be one of the possible ways to learn from spreading cases of self-organized action in the public realm.

\section{References}

Anderson WT (1999) Communities in a world of open systems. Futures 31(5):457-463

Blair R (2004) Public participation and community development: the role of strategic planning. Public Adm Q 28(1/2):102-147

Carmo A, Estevens A (2017) Urban citizenship(s) in Lisbon: examining the case of Mouraria. Citizsh Stud 21(4):409-424

Clark W (2000) Activism in the public sphere: exploring the discourse of political participation. Ashgte, Aldershot

Concilio G, Molinari F (2015) Place-based innovation: analysing the "social streets" phenomenon. In: Proceedings of the IFKAD 2015 conference. Bari, Italy, pp 10-12

Emery M, Flora C (2006) Spiraling-up: mapping community transformation with community capitals framework. Community Dev 37(1):19-35

Faraj S, Jarvenpaa SL, Majchrzak A (2011) Knowledge collaboration in online communities. Organ Sci 22:1224-1239

Flanagin AJ, Stohl C, Bimber B (2006) Modelling the structure of collective action. Commun Monogr 73(1):29-54

Følstad A (2008) Towards a living lab for development of online community services. J Organ Virtualness 10:47-58

Hayes-Conroy J (2008) Hope for community? Anarchism, exclusion, and the non-human realm. Polit Geogr 27:29-34

Hou J (ed) (2010) Insurgent public space: guerrilla urbanism and the remaking of contemporary cities. Routledge, New York

Karvonen A, van Heur B (2014) Urban laboratories: experiments in reworking cities. Int J Urban Reg Res 38(2):378-392

Kavanaugh A, Carroll JM, Rosson MB, Reese DD, Zin TT (2005) Participating in civil society: the case of networked communities. Interact Comput 17(1):9-33

Larson KL, Lach D (2008) Participants and non-participants of place-based groups: an assessment of attitudes and implications for public participation in water resource management. J Environ Manage 88(4):817-830

Leminen S (2013) Coordination and participation in living lab networks. Technol Innov Manag Rev Novemb $5-14$

Mulder, I (2012) Living labbing the rotterdam way: co-creation as an enabler for urban innovation. Technol Innov Manag Rev Sept 39-43

Olson M (1971) The logic of collective action: public goods and the theory of groups. Harvard University Press, Cambridge

Ostrom E (2006) The value-added of laboratory experiments for the study of institutions and common-pool resources. J Econ Behav Organ 61:149-163

Pattie C, Seyd P, Whiteley P (2003) Citizenship and civic engagement: attitudes and behaviour in Britain. Polit Stud 51:443-468

Schuler D (2010) Community networks and the evolution of civic intelligence. AI Soc 25(3):291-307

Staeheli LA (2008) Citizenship and the problem of community. Polit Geogr 27:5-21

Vromen A (2003) Community-based activism and change: the cases of Sydney and Toronto. City Community 2(1):47-68

Yau Y (2011) Collectivism and activism in housing management in Hong Kong. Habitat Int 35:327-334

Noelle-Neumann E (1974) The spiral of silence: a theory of public opinion. J Commun 24(2):43-51 